\title{
El proyecto cultural liberador de José Martí para su tiempo y para el siglo xxi"
}

\author{
Elmys Escribano Hervis**
}

\begin{abstract}
Recibido: 28 de julio de 2015
Evaluado: 31 de agosto de 2015 Aceptado: 28 de septiembre de 2015
\end{abstract}

\section{RESUMEN}

En el artículo se sostiene la validez y significación del proyecto cultural liberador de José Martí para América Latina. Se analiza desde el momento en que fue concebido a fines del siglo xix y para la actualidad. La determinación y defensa de los puntos de vista que se presentan han sido posibles mediante el análisis de la obra completa de José Martí recogida en los 28 tomos editados en 1963, por la Editorial Nacional de Cuba. El análisis textual de dichas fuentes lo completa su contrastación con el contexto condicionante de las últimas décadas del siglo xIx, especialmente en Cuba, México, Guatemala, Venezuela y Estados Unidos, sus contradicciones y tendencias de desarrollo. La exposición del contenido del artículo se ha estructurado en tres apartados: el primero es titulado "América Latina hasta fines del siglo XIX"; el segundo, “José Martí, su conocimiento y vocación latinoamericana"; y el tercero, "El proyecto cultural liberador martiano para América Latina en todos los tiempos". Se sostiene la idea de la libertad en José Martí como centro vital del proyecto de cambio y desarrollo para América Latina, en la que vertebró coherentemente su discurso cultural al que se integra la educación, la ciencia, la prensa y el arte, en distintas manifestaciones.

Palabras clave: José Martí, América Latina, proyecto cultural liberador, educación.

\footnotetext{
Artículo de reflexión. No tuvo financiación. Recoge resultados del autor por más de 20 años dedicado a la investigación en el tema. Cómo citar este artículo: Escribano Hervis, E. (2016). El proyecto cultural liberador de José Martí para su tiempo y para el siglo XXI. Hallazgos, 13(25), 65-87 (doi: http://dx.doi.org/10.15332/s1794-3841.2016.0025.03).

* Doctor en Ciencias Pedagógicas, del Instituto Central de Ciencias Pedagógicas, La Habana (Cuba). Profesor Titular (2007) de la Universidad de Matanzas (Cuba). Correo electrónico: escriba2003@gmail.com
} 


\section{The cultural project release José Martí for his time and for the XXI century}

\begin{abstract}
In the article the validity and significance of liberating cultural project for Latin America José Martí holds. It is analyzed from the moment he was conceived in the late nineteenth century to today. The determination and defense of the views presented, it has been possible by analyzing the masterpiece of José Martí contained in the 28 volumes published in 1963 by the National Publishing House of Cuba. Textual analysis of these sources is completed by its contrast with the conditioning context of the last decades of the nineteenth century, especially in Cuba, Mexico, Guatemala, Venezuela and the United States, its contradictions and development trends. The presentation of the content of the article is structured in three sections or sections: the first, Latin America until the late nineteenth century; the second, José Martí, knowledge and Latin American vocation; and the third Marti liberating cultural project for Latin America at all times. The idea of freedom in José Martí as a vital center of the project of change and development for Latin America in which coherently it integrated cultural discourse that education, science, media and art, various manifestations integrates holds.
\end{abstract}

Keywords: Jose Marti, Latin American, liberating cultural project, education.
Received: July 28, 2015

Evaluated: August 31, 2015

Accepted: September 28, 2015 


\section{O projeto cultural libertador de José Marti para o século XX: muito além do seu tempo}

Recebido: 28 de july de 2015

Avaliado: 31 de agosto de 2015 Aceito: 28 de setembro de 2015

\section{RESUMO}

Neste artigo sustentamos a validade e significação do projeto cultural libertador de José Marti para a América Latina. É analisado seu início, no final do século XIX até a atualidade. A determinação e defesa dos pontos de vista que apresentados são possíveis por meio a análise da obra completa de José Marti, os 28 volumes editados em 1963, pela Editora Nacional de Cuba. A análise textual dessas fontes completam seus contrastes com o contexto das últimas décadas do século XIX, especialmente em Cuba, México, Guatemala, Venezuela e Estados Unidos, suas contradições e tendências de desenvolvimento. $\mathrm{O}$ artigo se estruturou em três partes: o primeiro, intitulado "América Latina até o fim do século XIX", o segundo, "José Marti, seu conhecimento e vocação latino americana" e o último, "O projeto cultural libertador martiano para a América Latina em todos os tempos". O centro vital do projeto é mudança e desenvolvimento a partir da liberdade da América Latina, encaixando coerentemente seu discurso cultural a educação, a ciência, a imprensa e à arte, de diferentes formas.

Palavras-chave: José Marti, América Latina, projeto cultural libertador, educação. 


\section{INTRODUCCIÓN}

Nos adentramos en el siglo xxI; Latinoamérica sigue siendo una región de inequidades y contrastes de todo tipo. En varios países del continente Gobiernos de diferentes naturalezas han desarrollado programas de arraigo popular y tratan de responder a centenarias contradicciones e injusticias. Pesa demasiado el lastre de la deformación de las estructuras que legaron políticas en favor de la dependencia y que propiciaron el subdesarrollo de manera sostenida durante siglos (Galeano, 1979). La entrega incondicional ante el capital extranjero, la exportación de materia prima y la carencia de políticas que estimulen el desarrollo de la ciencia, la tecnología y la educación de todas las clases y sectores sociales de la nación, de acuerdo con nuestras necesidades más auténticas de bienestar y desarrollo, son algunos indicadores de los extravíos.

La exclusión y la alienación en dichos sectores es una problemática que no aparece recogida en las estadísticas (Pérez, 2003 ). El pensamiento social en ocasiones se muestra distante de estas problemáticas y todavía exhibe fuertes lazos con las tendencias actuantes, especialmente en Europa (Casañas, 2012). La ejecución de programas que se distingan por la autenticidad de la cultura y que aseguren las posibilidades de progreso pleno y sostenido a los sectores populares es una problemática difícil de concebir y concretar.

José Martí, quien conformó su obra y pensamiento como expresión de su amplio cosmopolitismo y muy especialmente por su profundo conocimiento de las condiciones de América Latina de su tiempo y de su historia, concibió una obra en la que proclamó su inquebrantable compromiso con los oprimidos y en la que de forma coherente expuso una visión acerca de la esencia de diferentes expresiones de la cultura que favorecen a la independencia y al desarrollo de los seres humanos y las naciones (Vitier, 1982). Su discurso se torna polisémico y en más de una ocasión algunos pensadores han hecho lecturas en acomodo a intereses bien distantes de los que defendió Martí en su tiempo y por los que ofrendó su valiosa vida. Le quedaron cosas por decir y por hacer que la agonía de la prisa no le permitió. No anduvo tampoco entre comodidades y francachelas, ni prestó su pluma a causa injusta. En tal sentido, el trabajo que se presenta fija como propósito valorar la integración y la significación del proyecto cultural liberador de José Martí para su tiempo y para las condiciones específicas de América Latina en el siglo xxI.

\section{Desarrollo}

\section{I}

\section{América Latina hasta fines del siglo xIX}

El arribo de América Latina a la modernidad la hizo desembocar en profundas contradicciones y conflictos en el orden del pensamiento y los proyectos de desarrollo e independencia que fueron concebidos en esta parte del mundo. El proceso de transición hacia nuevas formas de pensamiento emerge de la sociedad colonial. Inicialmente estuvo muy apegado al pensamiento europeo y además con un subrayado sesgo crítico y reformista. Fue un proceso de maduración y desarrollo sostenido. "El pensamiento ilustrado no surge bruscamente, en 
la forma antimetropolitana y librepensadora que adquirirá frecuentemente en vísperas de la independencia. Existen pasos previos, representados por peninsulares o criollos generalmente fieles a las monarquías y a la Iglesia Católica" (Chiaramonte, 1992, p. 16).

Los líderes que dieron los pasos fundadores fueron hombres ilustrados. Por momentos, expresan la continuidad de un régimen, por una parte, y por otra la ruptura con este, por lo innovador de su discurso sobre todo, por cuanto ello sustentaba sus intereses como grupo social que en esta coyuntura histórica se identifica con necesidades de la fundación de la nación. De este modo se cimentó también el pensamiento y la cultura que caracteriza el comienzo de la gesta libertaria continental. En la concepción de los hombres que pensaron la independencia se tejió una gran confianza en la educación y la cultura.

Los líderes revolucionarios y pensadores desde inicios del siglo XIX sostuvieron la educación popular como piedra angular del proceso de perfeccionamiento de los pueblos. Con el proceso de independencia, en todo el continente se manifestó la defensa de la educación popular como expresión de la idea que este importante cambio debía llegar a todos. "La educación popular debe ser el cuidado primogénito del amor paternal del Congreso [exclamó el Libertador en su discurso de Angostura] Moral y Luces son los dos polos de la República. Moral y Luces son nuestras primeras necesidades" (Bolívar, 1819, p .7).

Simón Bolívar asumió la educación como condición indispensable para ejercer derechos políticos, aspecto en el que coincidieron muchos líderes revolucionarios de la época. Estableció también una relación directa entre el carácter de la educación y el destino de la nación:

La nación será sabia, virtuosa, guerrera, si los principios de la educación son sabios, virtuosos y militares; ella será imbécil, supersticiosa, afeminada $\mathrm{y}$ fanática si se cría en la escuela de los errores. Por esto es que las sociedades ilustradas han puesto siempre la educación entre las bases de sus políticas (...) En efecto, las naciones marchan hacia el término de su grandeza con el mismo paso con que camina la educación. Ellos vuelan, si ella vuela; retrogradan; si retrograda; se precipitan y se hunden en la oscuridad; si se corrompe o absolutamente se abandona. (Bolívar, 1819) (Prieto, 2006, p. 78)

Los líderes del proceso de independencia latinoamericana defendieron ideales con un sano espíritu de mejoramiento y encauzamiento de la vida continental, pero en ocasiones sobrevaloraron el rol de la educación y la confianza en legislar para resolver y transformar. En este continente era más urgente la comprensión del drama existencial humano, dado en condiciones de vida, trabajo, verdadera independencia, dignidad y justicia, o sea, aspectos que crearían sólidas bases para articular sobre ellos una nueva educación (Fuentes, 2008).

El siglo XIx fue para América Latina un periodo de esencia épica; fueron frecuentes las guerras, las luchas, los encontronazos, los desplazamientos de seres humanos de sus lugares de nacimiento y por ende de sus culturas ancestrales. Hubo líderes que estuvieron imbuidos de pensamiento humanista y revolucionario que asumieron la utopía de concebir un mundo mejor, pero 
en su intento chocaron contra las más disímiles dificultades y crudas realidades continentales, lo que hizo que más de un anhelado proyecto quedara solo en el plano de las buenas intenciones. Hubo otros líderes, que sopesaron sus sacrificios en la contienda como elemento suficiente para hacerlos merecedores de privilegios y en tal sentido sus malogradas repúblicas fueron una extensión de la colonia.

Los hombres que encabezaron los movimientos de liberación, salvo unas cuantas excepciones como la de Bolívar, se apresuraron a tallarse patrias a su medida: las fronteras de cada uno de los nuevos países llegaban hasta donde llegaban las armas de los caudillos. Más tarde, las oligarquías y el militarismo, aliados a los poderes extranjeros $\mathrm{y}$ especialmente al imperialismo norteamericano, consumarían la atomización de Hispanoamérica. Los nuevos países, por lo demás, siguieron siendo las viejas colonias: no se cambiaron las condiciones sociales, sino que se recubrió la realidad con la retórica liberal y democrática. Las instituciones republicanas, a la manera de fachadas, ocultaban los mismos horrores y las mismas miserias. (Paz, 1993, p. 125)

La sociedad no pudo ser reformada con el rigor que reclamaban los distintos problemas sociales que gravitaban sobre el continente. Octavio Paz ha afirmado que esta época "Hispanoamérica fue una España sin España [...] Un feudalismo disfrazado de liberalismo burgués, un absolutismo sin monarca pero con reyezuelos: los señores presidentes" (Paz, 1993, p. 126).
Se revolucionaron las ideas, pero no se concretó nada en cambios sociales (Fuentes, 2008). Las necesidades de desarrollo humano, libertad, educación en correspondencia con lo que demandaban los campesinos, los negros, las mujeres y los mestizos no experimentaron cambios sustanciales en esta etapa. Con acierto, José Martí, apuntó en el ensayo crítico "Nuestra América” lo siguiente:

El continente descoyuntado durante tres siglos por un mando que negaba el derecho del hombre al ejercicio de su razón, entra, desatendiendo o desoyendo a los ignorantes que lo habían ayudado a redimirse, en un gobierno que tenía por base la razón; la razón de todos en las cosas de todos, y no la razón universitaria de unos sobre la razón campestre de otros. El problema de la independencia: no era el cambio de formas, sino el cambio de espíritu. (Martí, 1963, p. 19, Tomo VI)

Se manifestó en el continente a partir de esta etapa desarraigo, falta de vínculos entre los Gobiernos, los pueblos y sus realidades. El hombre natural de estas tierras y el mestizo eran desconocidos (Fuentes, 2008). Se llegó a identificar como un lastre para el ascenso a la ansiada civilización.

El problema del indio fue zanjado por el procedimiento gordiano en Argentina y Uruguay. Las batidas en gran escala se llevaron a cabo en 1829 al 32 por Rosas y en 1879 por Roca. Esta última vez se exterminaron más de veinte mil indígenas, asesinados por las tropas del ejército de línea a tiros de remington. (Martínez, s. f., p. 78). 
De acuerdo con la cultura impuesta por el grupo dominante en aquella fecha, el funcionamiento social desconocía la esencia humana de la base social con la que se hizo la independencia; en materia educacional, por ejemplo, existía un escuálido sistema sustentado en decretos y leyes extranjerizantes y ajenos a la realidad y a las necesidades de bienestar, independencia y desarrollo de los hombres naturales de estas tierras. En otros casos se mantenían obsoletos sistemas educativos en aquellas repúblicas.

La economía latinoamericana se mantuvo esencialmente con un carácter agrario. Se trabajaba en la tierra en función de productos primarios para obtener materia prima exportable. En este aspecto se observa una interesante relación dada entre el carácter de la producción agraria, la cultura que este proceso genera y las relaciones humanas que se forjan sobre la base de los procesos productivos. Ezequiel Martínez Estrada aporta una interesante mirada a la complejidad de este tema en la región:

Productos como el henequén, el banano, el azúcar y el caucho exigen formas de trabajo crueles e insalubres, en climas tórridos, en tierras húmedas propicias a enfermedades infecciosas y endémicas, además de una clase de tareas agotadoras.

Hay estrecha relación entre la clase de producción, las condiciones de trabajo y el dominio del capitalismo, según las regiones. De modo que en el área del café y el azúcar el trabajo es forzado si no es esclavo; en la del trigo y la carne es relativamente libre; en la del petróleo cosmopolita y asalariado, y en la de las frutas, especialmente el banano, mestizo y desamparado. Y como cultivo y cultura son sinónimos, en esas áreas se genera un tipo particular de vida espiritual, que ha podido designarse como civilización del café, del trigo o del banano. (s. f., p. 82)

Después de la independencia hubo dos pronunciamientos políticos de más clara identificación; por una parte, las tradicionales de espíritu conservador que estuvieron vinculados al Estado, su administración y burocracia, y una economía de hacienda que trata de recuperar posiciones; y frente a ellos se erigen los denominados liberales, con un espíritu renovador, con programas opuestos, en cierto sentido, a veces novedosos, implicaban un abandono de las formas tradicionales de la vida colonial hispánica y el consecuente repudio y oposición a esa herencia. Aunque la mayoría de los americanos por aquella fecha no llegaron a distinguir con precisión que diferenciaba a liberales de conservadores, el enfrentamiento entre estas fuerzas fue enconado en la mayoría de los casos.

Ambos partidos políticos tuvieron claridad del papel de la educación como instrumento de mejoramiento científico, técnico y material del país y reconocieron su papel como forjadora de hombres. Ni conservadores, ni liberales actuaron consecuentemente por mejorar la educación del hombre del campo, lo cual era necesidad obligada en un continente de economía agraria y de mayoritaria población rural, formada por campesinos e indios que no se interesaban en la economía monetaria. Ninguno de los dos partidos contribuyó a brindar una opción de participación educativa, cultural y política a estas masas humanas desplegadas en el continente. 
Benito Juárez (1806-1872), indio, campesino, abogado, profesor y hombre de Estado, en un país lleno de divisiones, con un clero vacilante que se protegía a la sombra de los militares y los intereses de los terratenientes, encarnó su rol histórico como pocos en el continente.

En su "Exposición al Soberano de Oaxaca" al abrir sus sesiones el 22 de julio de 1848, Benito Juárez abordó lo referente a la situación educativa en aquel Estado. Dichos puntos de vista fueron enriquecidos a través de los años siguientes en el desempeño de su liderazgo político (Juárez, 1971).

El Gobierno de Juárez invitó al doctor Gabino Barreda (1818-1881) a reorganizar la educación nacional. La obra de Juárez se distingue por la ampliación de la educación pública con carácter gratuito y laico en todo el país, y para ello hizo construir cientos de escuelas. Esto sucedió sobre todo después del 16 de enero de 1868, fecha cuando ocurrió su segundo mandato constitucional. En esta ocasión creó el despacho de instrucción pública, pues unido a su labor en pro de la educación, pretendía también la industrialización del país. Por esa fecha la población de México era de siete millones de personas, de las cuales cinco millones eran ignorantes y por demás, pobres. Solo unos ochocientos mil eran letrados (Fuentes, 2008). Estos elementos de carácter social animaron las leyes de la reforma. Este proceso tuvo un fuerte acento político y jurídico, pues se hacía corresponder con un cuerpo de leyes que amparó la legitimidad de la nacionalización de los bienes del clero; la concreción de la separación de la Iglesia del Estado; la secularización de los cementerios y las fiestas públicas; y lo que suele ser señalado como elemento central: la promulgación de la libertad de cultos. Todo ello tenía además como eje central una dimensión ética, que reclamaba el respeto a cada persona y a sus derechos esenciales.

Para disponer de los recursos requeridos para el proceso de ampliación educativa, o sea, la necesidad de escuelas y maestros, Juárez despidió a 60.000 militares — "maestros por soldados", decía-; también concibió la negociación del pago de la deuda extranjera con algunas naciones como Inglaterra. La educación, la alfabetización, la secularización y el laicismo fueron pilares fundamentales en su obra. Esto constituyó un duro golpe a la hegemonía hasta entonces inquebrantable del clero en el pensamiento, la cultura y la educación en México. Benito Juárez fundó la Escuela Nacional Preparatoria, con el propósito de abrir cause a la educación basada en la ciencia, lo cual tendría una importancia estratégica en el ordenamiento y el progreso de la nación mexicana. De este modo, se oponía también de forma concreta y eficaz a la influencia religiosa en la formación de los mexicanos.

El origen social de Juárez, y su especial sensibilidad para identificarse con la causa de los desposeídos, alienados y marginados, fue una condición esencial que lo presenta ante la historia como un protagonista y un líder indiscutible en la lucha por la igualdad de los derechos. En este aspecto debe subrayarse su rol como defensor de los derechos de las mujeres como una forma de mejoramiento social (Escribano, 2015).

Por su parte, Venezuela afrontaba una situación que a su vez era representativa de todo el continente. Existía una marcada incongruencia entre la educación y la cultura 
con la naturaleza y con su tiempo. Era incoherente la política de Gobierno para ofrecer posibilidades reales de desarrollo a los pueblos, así como una educación en arreglo a sus más auténticas necesidades. Lo antes dicho se manifestó de manera subrayada durante el Gobierno de Antonio Guzmán Blanco, quien se hiciera llamar "Ilustre americano". Este gobernante alentó una política de imitación de modas foráneas, especialmente francesas, desviando a ese país del cauce de su historia, cultura y verdadero desarrollo. Resulta ilustrativa la observación de José Martí, originada por el conocimiento que le propició su visita a Venezuela en 1881. Escribió que los pueblos de América estaban

Criados como parisienses, se ahogan en su país: no sabrían vivir bien más que en París. Son plantas exóticas en su propio suelo: lo cual es una desgracia [...] Cuando el pueblo en que se ha nacido no está al nivel de la época en que vive, es preciso ser a la vez el hombre de su época y el de su pueblo, pero hay que ser ante todo el hombre de su pueblo. (Martí, 1963, p. 154, Tomo XIX)

Sobre el dañino hábito de la imitación y el desarraigo, que observó en la Caracas de sus días de visita, también apuntó:

En la ciudad, una vida rara semipatriarcal, semiparisiense, espera a los forasteros. Las comidas que en ella se sirven, exceptuando algunos platos del país, las sillas para sentarse, los trajes que se usan, los libros que se leen, todo es europeo [...] se desdeña el estudio de las cuestiones esenciales de la patria;-se sueña con soluciones extranjeras para problemas originales; se quiere aplicar sentimientos absolutamente genuinos, fórmulas políticas y económicas nacidas de elementos completamente diferentes. (Martí, 1963, pp. 159-160, Tomo XIX)

Con el decursar del siglo xix en Latinoamérica y en años posteriores a la Guerra de Reforma en México, o a la Organización Nacional en Argentina, se intensificaron los empeños por incorporar a un número creciente de personas al eufemísticamente llamado género de la "Civilización". Por ello, se pensó en transformar estructuras e instituciones o formar docentes, lo cual se identificó como pasos concretos hacia el desarrollo.

Domingo Faustino Sarmiento, fue uno de los más altos defensores de la Educación Popular (Sarmiento, 1856). En el ideario y obra educativa de Sarmiento se observa su confianza en que la educación estimula el cambio de una Argentina ganadera a una agropecuaria. Asumió la educación como una función económica y social. Tuvo gran preocupación por la educación primaria como base de toda reforma. Sus viajes por Estados Unidos y Europa contribuyeron a cimentar una fervorosa admiración por la cultura angloamericana, razón que lo llevó a difundir a través de las cartillas las conquistas asombrosas de la revolución agrícola e industrial que conmovía a Estados Unidos. Ponderó parejamente a la maravilla de la técnica y la industria, la grandeza moral de esa nación, pues percibió esto como fruto o legado de la colonización inglesa.

Sarmiento escribió en Chile la obra Facundo para combatir desde el exilio la dictadura de Juan Manuel de Rosas, en ella se refleja los acontecimientos en Argentina desde la 
independencia, presentando como un país dividido y lastrado para el desarrollo a causa de la influencia negativa de la barbarie, en tal sentido señaló la oposición

[...] entre la civilización (refugiada en las ciudades, potencial de orden y progreso) y el medio pampeano, cuyos rudos habitantes (los gauchos) eran la manifestación viva del desorden ciego de la naturaleza. La esperanza transformadora de Argentina se identificaba con un programa de reconstrucción nacional, educativo, que salvase el abismo entre la sociedad civilizada y la que se había forjado al margen de ella en las provincias, la gauchada. (Sarmiento intentó, además, aplicar ese programa durante su mandato presidencial, en el período 1868-1874) (Interactivo, s. f. p. 227)

Las ideas de Sarmiento se distinguen por su acento racista y favorable a la colonización, pues para él América es "toldos de razas abyectas, un gran continente abandonado a los salvajes incapaces de progreso" (Fernández, f., p. 53). Y por si fuera poco lo anterior, agrega: "Para nosotros Colocolo, Lautaro y Caupolicán, no obstante los ropajes nobles y civilizados (con) que los revistiera Ercilla, no son más que unos indios asquerosos, a quienes habríamos hecho colgar ahora, si reapareciesen en una guerra de los araucanos contra Chile, que nada tiene que ver con esa canalla" (Fernández, s. f., p. 53).

La concepción de Sarmiento fue de una inspiración norteamericana y el pensamiento de otro argentino, Juan Bautista Alberdi, tuvo inclinación marcadamente europea. Sarmiento se sintió influenciado por la obra del educador norteamericano Horace Mann. En ambos casos se observa un pronunciamiento claro por practicar una política educativa y cultural de imitación a patrones foráneos y a manifestar desprecio sobre la composición racial y humana de Argentina de su tiempo; por tal razón, promovieron la inmigración europea y el desconocimiento o negación de su realidad autóctona.

Por su parte, Gregorio Weinberg es conclusivo al afirmar: "Las ideas educativas de Sarmiento, en su intento de ponerlos en su país, estaban indisolublemente ligados a una concepción que la integraba con una política inmigratoria y colonizadora" (1981, p. 141). La percepción de Sarmiento de la civilización se identifica con los valores de la cultura foránea; para él la barbarie era consustancial al hombre natural de estas tierras, al cual tildaba de ignorante, salvaje e incapaz de todo tipo de progreso y de la capacidad de vivir civilizadamente. Estos puntos, por demás racistas en extremo, han desatado a lo largo de la historia innumerables polémicas.

José Martí se opuso a la tesis de Sarmiento acerca de las contradicciones entre civilización y barbarie: "No hay batalla entre la civilización y la barbarie, sino entre la falsa erudición y la naturaleza" (Martí, 1963, p. 17, Tomo VI). Según Martí, la sustentación de este tipo de ideas encubre una visión colonialista de la historia y la sociedad,

[...] la civilización, que es el nombre vulgar con que corre el estado actual del hombre europeo, tiene derecho natural de apoderarse de la tierra ajena perteneciente a la barbarie, que es el nombre que los que desean la tierra ajena dan al estado actual de todo hombre que no es de Europa o de la América europea. (Martí, 1963, p. 442, Tomo VIII). 
Entre muchos intelectuales del continente se manifestó temprana admiración hacia la obra de Herbert Spencer; postulaban un ordenamiento social que permitiese superar el atraso económico y cultural - sobre todo de la población rural que seguía siendo la abrumadora y postergada mayoría-, así como la inestabilidad política.

De las últimas décadas del siglo xix vino el impulso político liberal con repercusiones en la economía, la ciencia, la educación y el pensamiento social. Esto propició en el orden del pensamiento y la cultura la apelación al positivismo. Esta fue la postura filosófica más socorrida en América Latina en esta etapa y desarrolló una notable influencia en la cultura, la ciencia, la educación y el pensamiento social en sentido general. Sobre este tema se han escrito variadas reflexiones desde distintos enfoques y posiciones metodológicas. Debe precisarse que esta corriente filosófica no fue asumida en Latinoamérica de forma mecánica, sino que ella fue objeto de una adecuación racional, lo que lleva a señalarse en ella una expresión sui géneris en el continente, incluso en cada país donde se tomó como fundamento del proceso de cambio. Uno de sus méritos en nuestro continente lo constituye el hecho de haber representado un fundamento racional para enfrentar la filosofía especulativa que precisamente en esa etapa pugna por echar raíces en el ámbito intelectual en América Latina (Zea, 1976).

El positivismo fue asumido y cultivado en Latinoamérica como una filosofía optimista, llena de confianza en el hombre, en la capacidad creativa de su pensamiento, en la cultura, en la ciencia, en el progreso y el desarrollo industrial; como una filosofía aliada del liberalismo y defensora de la democracia burguesa. Esas ideas resultaban muy avanzadas para los países latinoamericanos, recién liberados, en su mayoría, del colonialismo español y enfrascados entonces en profundas luchas entre las oligarquías retrogradas y la naciente burguesía nacional. (Guadarrama, 2008, p. 326)

Estas posiciones entraron en concordancia con los intereses de las débiles burguesías nacionales, que a su vez pretendían desarrollar formas premonopolistas de producción, la introducción de los adelantos de la ciencia y la tecnología, preconizada por los positivistas fue alzada como bandera por los políticos de turno y legitimizada en una carrera hacia el pretendido desarrollo.

Algunos representantes del positivismo latinoamericano asumieron la variante spenceriana reconocida como "darwinismo social". De una forma muy particular, asumieron la condición de indio o negro como pretendida inferioridad y un freno para el deseado desarrollo de los pueblos, prevaleciendo una confianza en la perfectibilidad del hombre, no abandonaron cierta posición de esencia racista, de lo cual ya se ha hablado en este texto. "La idea mexicana y latinoamericana del progreso en el siglo XIX fue por ello una cruel paradoja, queríamos ser parte, cuanto antes, de lo mismo que nos negaba. Nuestra negación, además, implicaba una alta dosis de racismo. No queríamos ser españoles, ni indios, ni negros" (Fuentes, 1997, p. 29).

La defensa de la educación como una especie de panacea a todos los problemas es un signo muy distintivo de esta corriente. Muchos de sus seguidores defendieron el 
derecho de la mujer a recibir educación y animaron el establecimiento de leyes y decretos para hacer igualitario y obligatorio el acceso a este servicio, pero los países no tenían la infraestructura escolar, ni siquiera de maestros indispensables para dar cobertura a todos los reclamos de este género. Resulta inobjetable que como consecución lógica a la idea mayoritaria en el continente de expandir la educación popular, la mejor forma de continuidad posterior, fiel por demás a la idea misma de la educación popular, es el positivismo. Sus definiciones y postulados de base en relación con sus ideas sociales aplicadas a la educación son coherentes con la situación de Latinoamérica de fines del siglo xIx.

Además de pretender el progreso y establecer a través de la educación el orden en países en situación de turbulencia social, también identificaron el ideal educativo preconizado por los positivistas la adopción de reformas y la recurrencia a patrones extranjeros en materia educativa. De este modo, América Latina cierra el siglo xix distanciándose de la esencia de la etapa de la emancipación, pues la política y el pensamiento social de este período abren claras expectativas a relaciones de dependencia. El lema del "orden y progreso" traería la asunción de postulados foráneos, para alcanzar la anhelada meta en los pueblos del Continente (Zea, 1980, p. 16).

El siglo XIX cerró con una marcada diferencia entre la educación que se dispensaba y las necesidades de desarrollo, de libertad y desalienación de nuestros pueblos. La educación de los hombres del campo continuó siendo un obstáculo insalvable a todos los modelos educativos y de desarrollo social practicado hasta la fecha. En 1900, el $54 \%$ de los habitantes de nuestra América eran analfabetos. El vínculo orgánico entre proyecto educativo-proyecto social de transformación del hombre continuaba ausente. Las políticas de desarrollo económico eran débiles e inestables, cuando no comprometidas con los intereses de alguna potencia extranjera (Escribano, 2015).

Complejo fue el panorama histórico de aquel momento como complejas y contradictorias las valoraciones de los efectos para el continente de la asunción del positivismo como filosofía que "guio" la educación y la cultura. A pesar de los yerros que provocó, y que situamos un ejemplo en este texto en las palabras de Leopoldo Zea, el positivismo señaló nuevos derroteros para el desestancamiento educacional de la Colonia y también del período posterior a la Independencia, en el que no se observaron cambios drásticos en este sentido. La confianza en la investigación, en la ciencia y en las posibilidades de perfectibilidad del hombre son puntos básicos por tener en cuenta en un debate acerca de esta forma de pensamiento filosófico en América Latina. En esta parte del mundo se asumió el positivismo desde una perspectiva latinoamericana y no como una práctica copiadiza y extraviada.

\section{II}

\section{José Martí, su conocimiento y vocación latinoamericana}

José Martí Pérez, hijo de emigrantes españoles, nació el 28 de enero de 1853, en la habanera calle Paula, barrio caracterizado por el mercadeo, el bullicio y el paso sistemático de militares españoles. Conoció la vida colonial de entonces y especialmente de los excesos e injusticias de los militares 
españoles que por entonces gobernaban con mano férrea la Isla de Cuba. Por otra parte, respiró la enrarecida atmósfera que cerraba puertas y negaba posibilidades de desarrollo a la nación y a cada cubano.

Su vocación de autodidacta y de lector impenitente le permitió acceder a la cultura universal, a la historia tanto en Cuba y en Europa, como de Estados Unidos y cada país de América Latina que visitó. El pensamiento de José Martí se identifica por la autonomía, la creatividad y la originalidad. De acuerdo con Reinerio Arce:

Existió un esfuerzo consciente en Martí por mantener la independencia de su pensamiento. Se pudiera concluir, por lo tanto, que Martí no es hombre de escuela ni de dogmas, sino hombre de ideas [...] Su pensamiento pudiera calificarse de abierto, integrador y dialéctico, sin que se le pueda poner etiqueta ni filiación a ninguna doctrina. (Arce, 1996, p. 138)

No debe ser etiquetado Martí en escuela alguna de pensamiento. "Cada pueblo se cura conforme a su naturaleza, que pide diversos grados de la medicina, según falte este $u$ otro factor en el mal, o medicina diferente. Ni Saint Simon, ni Karl Marx, ni Marlo, ni Bakunin. Las reformas que nos vengan del cuerpo" (Martí, 1963, p. 378, Tomo XII).

Fue Martí un humanista, pero un humanista práctico (Guadarrama, 2008); fue unhombre de ideas, poeta y orador; se elevó por encima de su creación, de su vocación al arte para liderar una revolución con y por los pobres de la tierra, pues tuvo la convicción de que con los oprimidos había que hacer causa común. (Martí, 1963, p. 19, Tomo VI).
Resultan de interés los juicios que emitió sobre Ralph Waldo Emerson, el trascendentalista americano, si se analizan desde la perspectiva de su propia vida y obra: "[Emerson] No obedeció a ningún sistema, lo que le parecía acto de ciego y de siervo [...] Se sumergió en la naturaleza, y surgió de ella radiante [...] Dijo lo que vio y donde no pudo ver, no dijo"' (Martí, 1963, p. 20, Tomo XIII).

Es evidente que la autonomía de pensamiento, así como la inspiración y respuesta a la naturaleza, lo asemeja a Emerson. Martí, que fue un profundo conocedor de la naturaleza en su expresión tanto de las islas del Caribe como en el continente, manifestó sentirse conmovido ante esta, no solo como inspiración poética y artística, sino también para entender la expresión cultural y la problemática social. En la primera parte de este breve contenido se citó a Ezequiel Martínez Estrada en su reflexión, que hace corresponder las problemáticas humanas con la actividad económica que propicia la naturaleza en su manifestación peculiar en cada región.

Una interpretación elemental de los siguientes versos, del poemarioVersos senci$l l o s^{3}$, lleva a pensar que prefiere nutrirse de las enseñanzas y dictados de la naturaleza como fuente primaria del conocimiento.

Yo sé de Egipto y Nigricia

Y de Persia y Xenofonte;

Y prefiero la caricia

Del aire fresco del monte.

Yo sé las historias viejas

Del hombre y de sus rencillas;

Y prefiero las abejas

3 Este poemario, según Luis Toledo Sande, tiene una inspiración autobiográfica. 
Volando en las campanillas.

(Martí, 1985, p. 237)

La corta estancia que tuvo en su niñez en los campos cubanos en Caimito del Hanábana lo puso en contacto con una magnífica expresión de la vegetación de esta zona del país y el modo de vida del campesino, así como las injustas e inhumanas prácticas que implicaba el tráfico de negros esclavos, que seguramente presenció en aquel paraje. Fue precisamente en los campos de Cuba, en contacto con sus bosques, sabanas, ríos y montañas donde vivió sus últimos días en 1895. Sus apuntes del diario (Martí, 1996) que llevaba en campaña constituye sin lugar a duda un monumento esencial de la cultura e identidad nacional, donde lo cubano cristaliza, a partir de su observación no solo del dagame o el fustete, sino del modo como discurre en su discurso lo cotidiano de la vida del campesino de entonces, sus prácticas y costumbres; de ese modo fecunda una peculiar expresión de la cultura.

Además de lo mencionado anteriormente, su estancia en México, Guatemala y Venezuela fue esencial para Martí en el proceso de conformación de su imagen y concepción de nuestra América. Conoció en esos países la abrupta y colorida naturaleza continental. Este fragmento del folleto "Guatemala", escrito en 1877, evidencia el asombro ante su observación del entorno, pues era aquella

[...] tierra de volcanes altos, de feraces cerros, de anchurosos ríos, donde el oro se extiende en placer vasto por las montañas de Izabal, donde el café-forma mejor del oro-crece aromoso y abundante en la ancha zona de la Costa Cuca. Allí la rubia mazorca crece a par de lo dorada espiga; colosales racimos cuelgan de los altos plátanos; variadísimas frutas llenan la falda de la gentil chimalapeña; obediente la tierra responde a los benéficos golpes del arado. Extraordinaria flora tupe la costa fastuosa del Atlántico (Martí, 1963, p. 118 , Tomo VII)

La concepción martiana de nuestra América fue un proceso paulatino, en el que intervino de manera esencial su conocimiento del hombre y la sociedad en todas las variantes que le proporcionó la vida desde su niñez, como ya se apuntó en la sociedad colonial de entonces, desde la vida urbana en la Habana, hasta su expresión rural en los campos cuando apenas contaba con nueve años de edad. Posteriormente su estancia en España, más tarde los países latinoamericanos que visitó y, por supuesto, Estados Unidos le brindaron vivencias y elementos suficientes para el conocimiento del hombre y las sociedades de entonces con sus contradicciones y desafíos.

La reflexión sobre el hombre es un tema recurrente en la obra del maestro. Consideró en el hombre el reflejo del ser social y lo individual actuante en él propiamente. Martí reconoció al hombre dentro de su cultura, por ello penetró en toda su realidad y sistema complejo de relaciones donde actúa. Distinguió al hombre natural, expresado en el mestizo, fiel a su autoctonía, como condición suprema de la identidad americana y habló también de criollos exóticos, aquellos que habiendo nacido en estas tierras vivían perpetuamente desdeñosos de su tierra $y$ su cultura con la mirada ansiosa allende el océano como destino promisorio de prosperidad y felicidad (Martí, 1963). 
Según José Martí a quien sus contemporáneos llamaron con justicia "Maestro" y también "Apóstol", el hombre natural de América es por naturaleza, bueno, artístico, amable, creativo y con alta espiritualidad. La educación y la cultura deben ajustarse de manera coherente a esta condición y además favorecerla. Conoció, además, en las sociedades de entonces a los diferentes grupos humanos sus creaciones artísticas, sus creencias y su actitud ante la sociedad, la naturaleza y ante sí mismos. "Y hasta que no se haga andar al indio, no comenzará a andar bien la América" (Martí, 1963, p. 33, Tomo VIII).

Completa la concepción martiana de nuestra América su percepción de la historia y la cultura de los pueblos de la región. Percepción que adquirió y consolidó con el paso de los años, además de sus estudios y vivencias en estas tierras. Resulta muy significativo que en la historia de la región destaca un pasado épico, pletórico de luchas por la libertad y desarrollo pleno. Es esta una historia de despojos, imposiciones e injusticias para hacernos dependientes y obedientes de los dictados de los amos, no importa el ropaje ni la procedencia de los mismos. En La Edad de Oro escribió en el artículo "Las ruinas indias":

No habría poema más triste y hermoso que el que se puede sacar de la historia americana. No se puede leer sin ternura, y sin ver como flores y plumas por el aire, uno de esos buenos libros viejos forrados de pergamino, que hablan de la América de los indios, de sus ciudades y de sus fiestas, del mérito de sus artes y de la gracia de sus costumbres" (Martí, s. f., p. 83)
Expresó su inquebrantable identificación con el pasado americano, como ya se dijo, marcado por la injusticia que cometieron los soldados españoles en su arremetida brutal en la batalla por el despojo y la obtención de riqueza rápida y fácil. "Con Guaicaipuro, Paramaconi, con Anacaona, con Hatuey hemos de estar, y no con las llamas que los quemaron, ni con las cuerdas que los ataron, ni con los aceros que los degollaron, ni con los perros que los mordieron" (Martí, 1963, p. 27, Tomo XXII).

Del conocimiento de la historia y la cultura de América Latina José Martí subrayó en su concepción lo que la distingue y expresa, y además extrajo valiosas lecciones para su labor liberadora, especialmente del proceso del que fue líder principal en la gesta decisiva de 1895. Fue consciente de los yerros que propicia la desunión, del aldeanismo y del desarraigo. La siguiente expresión ilustra lo antes dicho:

[...] los orígenes confusos, y manchados de sangre, de nuestra América [...] Del arado nació la América del Norte y la Española del perro de presa. Una guerra fanática sacó de la poesía de sus palacios aéreos al moro debilitado en la riqueza, y la soldadesca sobrante, criada con el vino crudo y el odio a los herejes, se echó, de coraza y arcabuz, sobre el indio de peto de algodón. Llenos venían los barcos de caballeros de media loriga, de segundones desheredados, de alféreces rebeldes, de licenciados y clérigos hambrones. Traen culebrinas, rodelas, picas, quijotes, capacetes, espaldares, yelmos, perros. Ponen la espada a los cuatro vientos, declaran la tierra del rey, y entran a 
saco en los templos de oro. Cortés atrae a Moctezuma al palacio que debe a su generosidad o a su prudencia, y en su propio palacio lo pone preso. La simple Anacaona convida a su fiesta a Ovando, a que viera el jardín de su país, y sus danzas alegres, y sus doncellas; y los soldados de Ovando se sacan de debajo del disfraz las espadas, y se quedan con la tierra de Anacaona. Por entre las divisiones y celos de la gente india adelanta en América el conquistador; por entre aztecas y tlaxcaltecas llega Cortés a la canoa de Cuauhtémoc; por entre quichés y zutujiles vence Alvarado en Guatemala; por entre tunjas y bogotáes adelanta Quesada en Colombia; por entre los de Atahualpa y los de Huáscar pasa Pizarro en el Perú: en el pecho del último indio valeroso clavan, a la luz de los templos incendiados, el estandarte rojo del Santo Oficio. (Martí, 1963, p. 136, Tomo VI)

Resulta muy elocuente la expresión martiana como conocer del pasado y los elementos culturales que identificó a cada pueblo en lo que fue para la historia un encontronazo violento, violatorio, mortal en muchos casos. De ese escenario y de la mezcla forzosa de sangres y culturas emergió la América actual; en tal sentido, José Martí, que fue un profundo conocedor del idioma español, escogió como mejor término para designar esta parte del mundo "nuestra América mestiza"(Martí, 1963, p. 19, Tomo VI), en alusión al crisol de culturas que ha sido y continúa siendo en nuestros días este continente. El mestizaje es la condición que mejor expresa a América Latina como colectivo humano; la cultura de esta parte del mundo es, por ende, una cultura esencialmente mestiza.
III

\section{El proyecto cultural liberador martiano para América Latina en todos los tiempos}

La trayectoria cosmopolita de la vida de José Martí, la multiplicidad de temas que abordó y el hecho de que su prematura muerte impidiera que él mismo organizara y sistematizara su obra son obstáculos para lograr una visión integral y completa de la esta. Se requiere la búsqueda afanosa en su epistolario y sobre todo su labor periodística publicada en la prensa de la época en casi todo el continente.

Al estudiar la obra de José Martí, sus discursos, cartas y sobre todo su obra periodística, se advierte la diversidad de temas tratados; sin embargo, aunque dirija lo escrito a un campo determinado de la actividad humana, existe una significativa coherencia en el discurso sin negaciones ni zigzagueos y siempre con aprehensiones culturales que resultan enriquecedoras del sentido de lo expresado.

El Apóstol, no escribió para satisfacer exigencias académicas, simplemente utilizó los medios disponibles, incluida también la creación literaria para reflejar, interpretar y valorar su época - una época de tránsitoen la profundidad de sus contradicciones y desafíos, los cuales llegan a nuestros días:

[...] logró captar la esencia de la crisis social de su tiempo - la de la revolución modernista - con una clarividencia y una intuición tan acertadas que todavía nos asombran sus reflexiones. Entendió mejor que sus contemporáneos que la suya era una época de 
“elaboración y transformaciones espléndidas", caracterizada, sin embargo, por un "desmembramiento de la mente humana" [...] En su obra coexisten la liberación ideológica y estilística, la imaginería onírica, la disgregación epistemológica, las rupturas lingüísticas, una soledad y angustia desgarradoras, la experimentación sobria, la autocontemplación creadora, el ritmo y la versificación renovadoras, la fe en la humanidad, el idealismo aunado al materialismo, y una insistencia sobre la revaloración de los elementos tradicionales de la literatura hispánica. (Schulman, 1994, p. 15)

Martí fue consciente que "De la independencia de los individuos depende la grandeza de los pueblos" (Martí, 1963, p. 124, Tomo VII). En este sentido, defendió la idea de que todas las fuerzas o influencias, especialmente la educación y la cultura, deben estar dirigidas a lograr hombres libres, independientes y autónomos. "La felicidad general de un pueblo descansa en la independencia individual de sus habitantes. Una nación libre es el resultado de sus pobladores libres" (Martí, 1963, p. 284, Tomo VIII).

Su experiencia personal de haber nacido en una nación colonial, haber sido desterrado a España, sus estancias de vida y trabajo en México, Guatemala y Venezuela, y sobre todo haber vivido por 15 años en Estados Unidos, le dieron vivencias sustanciales y elementos teóricos suficientes para valorar la necesidad de encauzar los esfuerzos y recursos necesarios para hacer a los hombres y a los pueblos libres en contextos donde la libertad podía ser percibida como un sueño distante.
Uno de los ejes fundamentales del ideario revolucionario de Martí, si no su piedra angular, es el imperativo moral de contribuir a la obra magna de la modernización socioeconómica del mundo, proyecto que, desde luego, comprendía la labor de transformar las estructuras sociales y políticas de América, de las islas del Caribe, y, de la colonia de Cuba. (Schulman, 1994, p. 44)

Para el Apóstol el acceso de los hombres a un trabajo y a través de él la obtención de una existencia plena y honrada es una condición vital en el camino de su independencia personal y a la vez la independencia del pueblo entero. Para cada pueblo es una necesidad habituar a los hombres al trabajo y a la creación. "[...] la condición de la felicidad es el trabajo, la libertad del individuo la condición de la libertad de la República" (Martí, 1963, p. 309, Tomo VII). En relación con el tema, las siguientes palabras también resultan ilustrativas: "Quien quiera nación viva, ayude a establecer las cosas de su patria de manera que cada hombre pueda labrarse en un trabajo activo y aplicable una situación personal independiente. Que cada hombre aprenda a hacer algo de lo que necesitan los demás" (Martí, 1963, p. 285, Tomo VIII).

En la época de Martí el único medio masivo de difusión que existía era la prensa. Su labor periodística es notable, desde su iniciación de forma estable en México hasta las crónicas escritas desde Estados Unidos o la obra fundadora del periódico Patria; es un trabajo germinal de reflejo de la realidad de su tiempo, de sus contradicciones y desafíos más agudos (Jiménez, 1993). Su trabajo en este orden puede ser calificado como revolucionario, pues marca un hito del modo de hacer periodismo, incluso hoy día 
(Rodríguez, 2012). Tuvo absoluta claridad del papel de la prensa y de su influencia en los modos de pensar y apreciar la realidad.

En el periódico, en la cátedra, en la academia, debe llevarse adelante el estudio de los factores reales del país. Conocerlos basta, sin vendas ni ambages; porque el que pone de lado, por voluntad u olvido, una parte de la verdad, cae a la larga por la verdad que le faltó, que crece en la negligencia, y derriba lo que se levanta sin ella. Resolver el problema después de conocer sus elementos, es más fácil que resolver el problema sin conocerlos. (Martí, 1963, p. 18, Tomo VI)

Desde este punto de vista se puede entender por qué dedicó tantos esfuerzos y atención a su trabajo en la prensa y por qué hubo momentos, como en la década de los años ochenta, en los que reportaba y escribía para más de 20 órganos de prensa de manera simultánea. "Martí fue el cronista hispanoamericano mejor informado sobre la vida y la cultura de los Estados Unidos en los últimos decenios del siglo XIX" (Schulman, 1994, p. 29). También se entiende el sentido de esta afirmación suya, que escribió a través de Patria en 1894: “Es preciso que se sepa en nuestra América la verdad de los Estados Unidos. Ni se debe exagerar sus faltas de propósito, por el prurito de negarles toda virtud, ni ha de esconder sus faltas, o pregonarlas como virtudes" (Martí, 1963, p. 290, Tomo XXVIII).

Fue un defensor de que todos, hombres y mujeres, tuvieran acceso parejo a la instrucción como una suerte de taller para el pensamiento y a la educación que preparara el hombre para la vida y le brindara las herramientas necesarias para marchar por la vida con independencia. Martí entendió el acceso a la educación como una condición para la independencia, de todos los sectores sociales en correspondencia con las condiciones y exigencias de vida y desarrollo en el contexto donde viven. En noviembre de 1883, en La América, vio la luz el artículo "Escuela de electricidad", en el cual realizó una profunda crítica a la inconformidad de la educación que se dispensaba en una época y las necesidades de esa época. En ese artículo expresó que:

Educar es depositar en cada hombre toda la obra humana que le ha antecedido: es hacer a cada hombre resumen del mundo viviente, hasta el día en que vive: es ponerlo a nivel de su tiempo, para que flote sobre él, y no dejarlo debajo de su tiempo, con lo que no podrá salir a flote; es preparar al hombre para la vida. (Martí, 1963, p. 281, Tomo VI)

¿Cómo interpretamos la idea martiana de educar como preparación del hombre para la vida? (Escribano, 2006).

Su concepción de la educación se vertebró y diseñó en función de la especificidad del hombre americano, de la tradición de pensamiento humanista que recepcionó, de las condiciones y de las necesidades del continente y de la conformación del concepto de nuestra América.

Según Martí, la educación debe desarrollarlas potencialidades y fuerzas naturales, tanto en cada individuo como en los pueblos. La educación como proceso social garantiza la transmisión de la experiencia histórico-social de una generación a otra. Este proceso de formación humana debe posibilitar 
la preparación científica, técnica y cultural del hombre con respecto a la época en la que vive; debe también habilitar al hombre de medios personales (conocimientos, hábitos y habilidades) para vivir de su trabajo honradamente. Martí pensó también dentro de su concepción el desarrollo espiritual del hombre.

Forma parte de la concepción martiana de la educación la idea de desarrollar la inteligencia como atmósfera natural en la vida del hombre, así como la capacidad de crear en cada individuo y en los pueblos. Así mismo, insistir en la necesidad de habilitar al hombre para aprender por sí mismo, incentivando el autodidactismo. Para José Martí la educación debe estimular al hombre a pensar por sí, a ser honesto, honrado, virtuoso y a vivir con decoro; y a la vez, poner coraza contra el egoísmo, la vanidad, la servidumbre, la codicia; prever extravíos como la ignorancia y evitar la manipulación y la dependencia.

Por otro lado, Martí dedicó tiempo y esfuerzos para escribir en el verano de 1889 La Edad de Oro. En esta obra ofreció a la niñez latinoamericana de entonces $-y$ ofrece a la de hoy día - poesía, cuentos y artículos variados, que aportan elementos de saber sobre ciencia, historia y otros temas conducidos por una forma de narrar de altos valores estéticos, que hacen entrar por el camino de la belleza y calan más hondo sus sabias enseñanzas éticas y profecías morales.

Martí le confirió a este proyecto alternativo una importancia trascendente, pues en ella pondría todo lo fecundo que en él ya había madurado. En una carta a Manuel Mercado fechada en Nueva York, 3 de agosto de 1889, escribió:
[La Edad...] lleva pensamiento hondo y ya que me la echo a cuestas, que no es poco peso, ha de ser para que ayude a lo que quisiera yo ayudar, que es a llenar nuestras tierras de hombres originales, criados para ser felices en la tierra en que viven, y vivir conforme a ella, sin divorciarse de ella, ni vivir infecundamente en ella, como ciudadanos retóricos, o extranjeros desdeñosos nacidos por castigo en esta otra parte del mundo. El abono se puede traer de otras partes; pero el cultivo se ha de hacer conforme al suelo. A nuestros niños los hemos de criar para hombres de su tiempo, y hombres de América. (Martí, 1963, p. 147, Tomo XX)

Una cualidad esencial que debía tener la educación que se requería en el continente es la cientificidad. Concibió que en la vida y en la enseñanza que se dispense en la escuela se debiera desterrar todo lo escolástico y sustituirlo por lo científico.

Que se trueque de escolástico en científico el espíritu de la educación; que los cursos de enseñanza pública sean preparados y graduados de manera que desde la enseñanza primaria hasta la final y titular, la educación pública vaya desenvolviendo, sin merma de los elementos espirituales, todos aquellos que se requieren para la aplicación inmediata de las fuerzas del hombre a la naturaleza. -Divorciar el hombre de la tierra, es un atentado monstruoso. $\mathrm{Y}$ eso es meramente escolástico: ese divorcio. -A las aves, alas; a los peces, aletas; a los hombres que viven en la Naturaleza, el conocimiento de la Naturaleza: ésas son sus alas. 
Y el medio único de ponérselas en hacer de modo que el elemento científico sea como el hueso del sistema de educación pública.

Que la enseñanza científica vaya, como la savia en los árboles, de la raíz al tope de la educación pública. -Que la enseñanza elemental sea ya elementalmente científica. (Martí, 1963, p. 278, Tomo VIII)

En su concepción de preparar al hombre para la vida, de integrarlo a su tiempo y cultura, y con ello contribuir a la independencia, desempeña un rol importante la ciencia. "El primer elemento desalienador al que Martí rindió tributo fue a la ciencia" (Guadarrama, 2008, p. 371). En este sentido, la ciencia debe ser un elemento puesto al servicio de mejorar la vida de cada hombre y de toda la humanidad y de integrar al hombre a su entorno y a su época.

La introducción de lo científico en la educación, para Martí, no se concretaba solamente en la inserción de los contenidos de ciencia en los programas escolares, sino que se concretaba en el enfoque científico del proceso educativo, en el estilo sencillo y práctico de la enseñanza, en atención a los problemas de la vida, a lo útil, al desarrollo, en llevar la ciencia como "savia", como "espíritu", como fundamento del proceso de formación del hombre, donde esta se manifieste no solo en lo que estudia, sino también en cómo se estudia; o sea, con qué espíritu se enfrenta la enseñanza: "Y no está la reforma completa en añadir cursos aislados de enseñanza científica a las universidades literarias; sino en crear universidades científicas, sin derribar por eso jamás las literarias; en llevar el amor a lo útil, y la abominación a lo inútil, a las escuelas de letras; en enseñar todos los aspectos del pensamiento humano en cada problema"(Martí, 1963, p. 282, Tomo VIII).

A la educación científica Martí la demandó no solo en la escuela, sino a través de la vida misma, en el seno de la familia, en las lecturas de libros y revistas. Él mismo escribió sobre variados temas de ciencia y fue director de la revista de divulgación científica La América en Estados Unidos. Como ya se apuntó, un rasgo esencial de la obra y el pensamiento de José Martí es su carácter revolucionario. Integralmente revolucionario. No se asume lo revolucionario solo en su acepción de cambio político-social, sino como espíritu renovador de cambio y transformación radical con el que enfrentó la escritura, el periodismo, la educación, la oratoria, la ciencia o el arte. En el arte, citamos la percepción que tuvo del teatro y del carácter y función social que reclamaba de este arte Latinoamérica: en primer lugar, según Martí, el teatro debe estar muy vinculado a la naturaleza y singularidad del hombre de estas tierras, sus problemáticas y desafíos.

La vida americana no se desarrolla, brota. Los pueblos que habitan nuestro Continente, los pueblos en que las debilidades inteligentes de la raza latina se han mezclado con la vitalidad brillante de la raza de América, piensan de una manera que tiene más luz, sienten de una manera que tiene más amor, y han menester en el teatro-no de copias serviles de naturalezas agotadas-de brotación original de tipos nuevos. (Martí, 1963, p. 200, Tomo VI)

Tomando como referencia su conocimiento de la sociedad mexicana de entonces, señaló que 
México necesita una literatura mexicana. Si anda México escaso en actores propios, consecuencia justa es ésta de la escasez y apartamiento de propios autores. La independencia del teatro es un paso más en el camino de la independencia de la nación. El teatro derrama su influencia en los que, necesitados de esparcimiento, acuden a él. ¿Cómo quiere tener vida propia y altiva, el pueblo que paga y sufre la influencia delos decaimientos y desnudeces repugnantes de la gastada vida ajena?

La literatura es la bella forma de los pueblos. Con pueblos nuevos, ley es esencial que una literatura nueva surja (Martí, 1963, p. 200, Tomo VI)

Sobre este tema volvió más tarde, en 1881, en ocasión de su estancia en Venezuela, escribiendo para la Revista Venezolana, a la que le dio vida y abordó desde sus páginas importantes temas relacionados con la cultura, el sentido del arte y su esencia en nuestros países en la coyuntura social y cultural de entonces.

Su literatura y su visión sobre la función social de esta, así como de la poesía, el teatro, la plástica y demás artes, están comprometidas con la independencia de los pueblos, hecho que favorece la idea de consolidar la autoctonía, la identidad y cultura propias. Relacionada con esta máxima, según se ha visto de manera breve, está su concepción sobre la prensa y la ciencia, así como la educación. Las aprehensiones culturales que el hombre realiza en su tiempo y en su contexto son alimento esencial para el desarrollo de su espiritualidad y de su independencia (Escribano, 2014).
El Apóstol solucionó como ningún otro contemporáneo el interrogante: ¿cómo vincular historia, cultura y proyecto educativo? Pues él fundamentó su proyecto de renovación y modernización para América a través de la historia, la tradición y la cultura, señalando los signos más vitales de la identidad latinoamericana. La concepción de la educación que fundamentó José Martí está en concordancia con la naturaleza y con los elementos que expresan la tradición y la cultura autóctona del continente. Una cultura que se identifica y expresa como mestiza. La América desde el siglo xvi fue, al decir del escritor brasileño Jorge Amado, una especie de inmenso lecho, que comprendió la violación y la violencia, y el nacimiento con ellas de razas de tipos nuevos y con estas razas, modos de hacer y culturas que expresaron una capacidad asimilativa, de síntesis, de contraconquista, de resistencia y de recreación. Fue un producto original y como tal exige una educación distinta, nueva (Escribano, 2006, p. 87).

La inventiva caracterizó al hombre natural de América, este tuvo respuestas originales a las preguntas de su entorno y de sí mismo, y en este sentido se plantea una máxima importante: si el hombre natural de América ha sido creativo y lo es por naturaleza, la educación que se dispense ha de estimular la creatividad y la inventiva como rasgos de la mejor tradición humana del continente. El Apóstol distinguió a América como: "la tierra de los rebeldes y los creadores" (1963, p. 371, Tomo VII). De esta manera, se opuso a la imitación y defendió la realización de la vida en correspondencia con la naturaleza continental. 
El discurso martiano está en espera de un diálogo más dinámico y sistemático con las condiciones histórico-concretas del siglo xxi y sus desafíos. La idea de la independencia, su confianza en el hombre, el rol de la historia y la cultura, la educación y la ciencia, así como el rol de la buena prensa y el arte son influencias que relacionadas coherentemente en épocas de tantos cambios y de una arrasadora presencia neoliberal (Guadarrama, 2005) esperan por nuestra actuación y nuestros más nobles empeños de labrar una mejor vida.

\section{Conclusiones}

La idea de la independencia es un elemento raigal en la obra de José Martí. Hacia ese fin confluyen todos sus esfuerzos y creaciones. Su proyecto de liberar a Cuba y a Puerto Rico del colonialismo pasaba a través de un empeño mayor: hacer a los pueblos de América Latina independientes en todos los órdenes de la vida y desarrollar de ese modo una vida plena para todos los nacidos en esta parte del mundo.

La percepción del proyecto cultural liberador en la obra de José Martí y su apreciación en las circunstancias históricas de finales del siglo XIX es una interpretación que se ajusta a la visión de los vencidos en una porfiada fe de resistencia por intentar vivir en paz, en equilibrio con la naturaleza, en equilibrio con otros pueblos y culturas, y en una casi fanática creencia en las posibilidades de mejoramiento del ser humano en el reino de este mundo, de lo cual Martí con su vida y pensamiento dio valiosas muestras.

\section{REFERENCIAS}

Arce, R. (1996). Religión: poesía del mundo venidero: implicaciones teológicas en la obra de José Martí. Ecuador: Ediciones CIAI.

Casañas, M. (2012). Introducción al estudio del pensamiento latinoamericano. La Habana: Pueblo y Educación.

Chiaramonte, J. C. (1992). Pensamiento de la ilustración. Economía y sociedad iberoamericana en el siglo XVIII (2da. edición). Caracas: Biblioteca Ayacucho.

Escribano, E. (2006). La concepción de la educación en la obra de José Martí. La Habana: Pueblo y Educación.

Escribano, E. (2014). Educación espiritual, conciencia de sí y libertad en la obra de José Martí. En R. Yáñezy J. Visotsky (Eds.), Tomar la escuela (pp. 57-72). Santiago de Chile: Quimantú.

Escribano, E. (2015). Elementos esenciales de historia de la educación latinoamericana [inédito].

Fernández, R. (s. f.) Calibán. Contra la leyenda negra. España: Edicions de la Universitat de Lleida Director de la Colección Ensayos/Scriptura: Jordi Jové.

Fuentes, C. (1997). Por un progreso incluyente. México, D. F.: Instituto de Estudios Educativos y Sindicales de América.

Fuentes, C. (2008). El espejo enterrado. México, D. F: Fondo de Cultura Económica.

Galeano, E. (1979). Las venas abiertas de América Latina(2da. edición). La Habana: Casa de las Américas.

Guadarrama, P. (2005). Desafíos educativos y culturales de la globalización para América Latina. Osaka: Yamada Mutsuo. 
Guadarrama, P. (2008). Humanismo práctico y desalienación en José Martí. En Pensamiento filosófico latinoamericano: humanismo vs alienación (pp. 360-362). Caracas: El Perro y la Rana.

Guadarrama, P. (2008). Significación del positivismo en América Latina. En Pensamiento filosófico latinoamericano: humanismo vs. alienación (pp. 326 - 340) Caracas: El Perro y la Rana.

Interactivo, M. (s. f.). Enciclopedia de Ciencias Sociales. Barcelona: Océano.

Jiménez, J. (1993). La raíz y el ala. Aproximaciones a la obra literaria de José Martí. Valencia: Pre-Textos.

Juárez, B. (1971). Documentos, discursos y correspondencia. México, D. F.: Secretaría del Patrimonio Nacional.

Martí, J. (1963). Obras completas. La Habana: Editorial Nacional de Cuba.

Martí, J. (1985). Poesía completa. La Habana: Letras Cubanas. Martí, J. (1996). José Martí. Diarios de campaña. La Habana: Casa Editora Abril.

Martí, J. (s.f.). La Edad de Oro. La Habana: Gente Nueva.

Martínez, E. (s. f.). Diferencias y semejanzas entre los países de la América Latina.Caracas: Biblioteca Ayacucho. S. A.

Martínez, L. E. (2007). José Martí y la ciencia en "Darwin ha muerto". Honda, (20), 38-44.

Paz, O. (1993). Los hijos del limo(4ta. edición). Barcelona: Seix Barral

Pérez, F. (enero-junio de 2003 ). Pobreza y exclusión: principales actores de la problemática educativa latinoamericana y caribeña. Cuadernos de Nuestra América, XVI(31), 95-126.

Prieto, L. B. (2006) El magisterio americano de Bolívar. Caracas: Fundación Biblioteca Ayacucho.

Rodríguez, P. P. (2012). El periodismo como misión. La Habana: Pablo de la Torriente, Centro de Estudios Martianos.

Sarmiento, D. F. (1856). Memorias sobre educación común presentada al Consejo Universitario de Chile. Santiago de Chile: Imprenta del Ferrocarril.

Schlachter, A. (1995). Martí en las ciencias. La Habana: Científico Técnica.

Schulman, I. (1994). Relecturas martianas: narración y nación. Amsterdam, Atlanta: Rodopi B. V.

Toledo, J. (1994). La ciencia y la técnica en José Martí. La Habana: Científico Técnica.

Vitier, C. (1982). Temas martianos. Segunda serie. La Habana: Letras Cubanas, Centro de Estudios Martianos.

Weinberg, G. (1981). Modelos educativos en el desarrollo histórico de América Latina. Buenos Aires: UNESCO, ONU, PENUD, CEPAL. Buenos Aires: Unesco, Organización de Naciones Unidas[ONU],Programa de las Naciones Unidas para el desarrollo [PNUD], Comisión Económica para América Latina y el Caribe[Cepal].

Zea, L. (1976). El pensamiento latinoamericano. Barcelona: Ariel.

Zea, L. (1980). Pensamiento positivista latinoamericano.Caracas: Cromotip. 